ISSN $1415-8973$

\title{
Análise de dados do Latim no Livro Velho do Tombo
}

\author{
Analysis of Latin data in the Old Book of Tombo \\ Gustavo Santos Matos* \\ Universidade Federal da Bahia, Salvador, Brasil \\ Célia Marques Telles** \\ Universidade Federal da Babia, Salvador, Brasil
}

\begin{abstract}
Resumo: O Livro Velho do Tombo, objeto de análise deste trabalho, arrola documentos como: "doaçoens, escripturas de terras, autos de posse, testamentos, sentenças, despachos, quitações, petições", entre outros, todos de teor jurídico. O trabalho aqui proposto propõe observar qual a função do uso das notae iuris no fazer notarial no Brasil Colônia presentes no Livro Velho do Tombo elencando e classificando os elementos latinos presentes nos cem primeiros fólios deste livro, seguindo a proposta de Célia Telles e Risonete Souza em trabalho sob o título: De verbo ad verbum: o uso do latim no Livro Velho do Tombo, no qual analisaram o uso do latim no documento Sentença da legacia que alcançou este Conu(en)to contra o P(adr)e Andre lobato da mata sobre bumas terras na Vila velha (fólios 70r -78r), classificando-os em: lexias simples, locuções, colocações e argumentos. Todo o trabalho será feito a partir da edição semidiplomática do livro. A partir dos textos editados, proceder-se-á ao levantamento dos trechos, termos, palavras e expressões escritos em língua latina. Seguindo o levantamento e a funcionalidade discursiva destes termos, brocardos jurídicos e trechos encontrados, fazer-se-á a separação, seguindo a categorização proposta por Telles e Batista. Busca-se com este estudo verificar se a classificação proposta pelas autoras é aplicável também a todos os documentos aqui analisados, visando melhor compreender as práticas notariais na Bahia Colônia.
\end{abstract}

Palavras chave: Filologia Textual. Mosteiro de São Bento. Latim. Livro Velho do Tombo.

\begin{abstract}
The object analized in this paper, the Livro Velho do Tombo, holds many different juridical documents. This paper aims to observe how latin elements are showed and used in this material cataloging and classifying all them contained in the first forty-six documents from Livro Velho do Tombo. The classifying process will follow the separation purposed by Célia Marques Telles and Risonete Batista de Souza in the paper call: De verbo ad verbum: o uso do latim no Livro Velho do Tombo. They sort in four classes the latin elements in the document "Sentença da legacia que alcançou este Conu(en)to contra o P(adr)e Andre lobato da mata sobre humas terras na Vila velha" (70r - 78r): simple words, locutions, collocations and arguments. A semi-diplomatic transcription is the base of the research. Following the elements are cataloged and classified according to the theorists proposal. Verify this proposal in all documents hold in the Livro Velho do Tombo is the main goal in this research, also trying to understand the notarial custom in the colonialist Bahian society.
\end{abstract}

Keywords: Philology. São Bento Abbey. Latin. Livro Velho do Tombo.

\section{MOSTEIRO DE SÃO BENTO}

Fundado em 1582, representando o desejo de afirmação da fé cristã, o Mosteiro de São Bento da Bahia foi o primeiro cenóbio beneditino edificado em todas as Américas. Sua presença no cenário da sociedade baiana e brasileira foi de grande importância para o progresso da região e para a criação de uma identidade marcante e própria.

Atuante por mais de quatrocentos anos o Mosteiro de São Bento foi um dos grandes precursores da intelectualidade em terras brasileiras. Grande disseminador de conhecimento detém um dos maiores acervos bibliográficos do Brasil, irradiador de cultura e sapiência no cenário cultural baiano. Toda essa importância deve-se também por sua primaz participação na atividade acadêmica no Novo Mundo (LOSE, 2006).

Aos monges baianos foi legada a tradição bibliográfica, possuindo, em seus acervos, grandes raridades documentais do Brasil, salvaguardando, assim, em seu interior, a memória de uma Bahia pretérita.

*Estudante de mestrado do Programa de Pós-Graduação em Língua e Cultura. Email: gsm.gustavus@gmail.com.

** Doutora, professora Titular de Filologia Românica do Instituto de Letras da Universidade Federal da Bahia, Pesquisadora do CNPq. Email: cmtelles@ufba.br. 
Toda essa história escrita integra o Acervo de Obras Raras da biblioteca do Mosteiro de São Bento da Bahia, sendo esta "uma das três únicas bibliotecas tombadas pelo Patrimônio Artístico e Histórico Nacional” (IPHAN) (TELLES, 2008). Sua tênue e intrínseca presença na sociedade baiana fez do Mosteiro uma das mais importantes instituições na história da Bahia.

Dos muitos documentos do Arquivo do Mosteiro de São Bento da Bahia, os Livros do Tombo do Mosteiro de São Bento da Bahia, uma coleção de seis livros, reconhecidos como Patrimônio da Cultura Mundial pela UNESCO, guardam em suas seculares páginas muito da história da cidade de Salvador da Bahia. Um, deste total de seis livros, será objeto da análise que ora se propõe apresentar: o Livro Velho do Tombo (citado LVT).

\title{
2 O LIVRO VELHO DO TOMBO
}

O LVT é um documento de grande importância, tanto linguística, como social e jurídica. Tem 215 fólios, sendo 193 escritos no recto e no verso. Esses registros de teor jurídico, com inúmeras referências sociais, culturais, geográficas, históricas e políticas, são documentos notariais que trazem fatos de língua do Brasil Colônia.

O Livro Velho do Tombo arrola documentos como: "doaçoens, escripturas de terras, autos de posse, testamentos, sentenças, despachos, quitações, petições", entre outros. Os documentos trasladados no Livro Velho do Tombo datam, na sua origem, do século XVI ao século XVIII. Foi escrito em tinta ferro-gálica, em escrita cursiva, por diferentes mãos. Contém o traslado de 92 documentos. O objetivo do LVT era, e continua sendo, a salvaguarda dos documentos originais, em sua essência. Estas cópias, por sua vez, são datadas do início do século XVIII, de 1705.

A intenção do Dom Abade era, desse modo, tombar (registrar) para documentar com fé pública, fazendo copiar (trasladar) as cartas de sesmarias e as escrituras relativas ao patrimônio do Mosteiro, reduzindo a dois livros os documentos anteriores. O traslado pressupõe que os documentos originais podem não mais existir hoje devido aos mais variados estragos neles, já evidenciados àquela época. Desse modo, para o trabalho que ora se propõe, denominam-se originais os traslados do Livro Velho do Tombo.

As palavras de Maria de los Ángeles Martínez Ortega (1999) que nos fazem recordar qual é a função primordial de um documento jurídico e nos leva à vontade expressa do Dom Abbade: tornar válido um processo entre duas ou mais pessoas ou organismos, observando primordialmente que estes tenham a maior autenticidade e garantia possível:

\begin{abstract}
Así, pues, para dar validez y solemnidad a este tipo de documentos y para hacer alarde de su conocimiento de la lengua latina, los notarios y escribanos aluden a términos latinos y espresiones brocárdicas que configuran este tipo de lengua ${ }^{1}$. (MARTÍNEZ ORTEGA, 1991, p. 43).
\end{abstract}

\section{O LATIM E O FAZER NOTARIAL BRASILEIRO}

O latim e o Direito são elementos indissociáveis, pelo menos no que tange ao mundo ocidental,onde o Império Romano se fez presente, e isto remonta a muitos e longos anos atrás. O Corpus Iuris Civilis é a base daquilo que hoje compreendemos como Direito em boa parte do mundo. Lopes (2011) afirma que "se nos mantivermos entre o segundo século antes de Cristo e a morte do último jurista citado no Digesto, teremos um período de

\footnotetext{
1 Tradução: "Assim, pois, para dar validade e solenidade a este tipo de documentos e para fazer alarde de seu conhecimento da língua latina, os notários e escrivães aludem a termos latinos e a expressões brocárdicas que configuram este tipo de língua".
} 
aproximadamente 450 anos" de desenvolvimento do saber jurídico, e,isto, desconsiderando Justiniano, pois, adicionaríamos 300 anos aos 450 já mencionados anteriormente. Daí já se pode perceber quão antiga é a ciência das leis. E por ter se desenvolvido no seio do Império Romano, envolvido pelo latim, língua que se utilizava em todo o mundo romano, àquela época, nada mais natural que o Direito tenha uma íntima relação com a língua latina.

Relação esta que atravessou séculos. Nem o tempo, nem os acontecimentos históricos, nem mesmo o desuso do latim como língua corrente, foram capazes de separar a língua latina do Direito. Atravessou a Idade Média, adentrou pela Modernidade e até hoje a língua vive no fazer jurídico. Prova disso são os provérbios e alguns termos latinos que, ainda hoje, não só existem como são comumente utilizados por juristas, magistrados, advogados, enfim, todos aqueles que recorrem ao Direito ou se valem dele.

A fim de atestar este uso inextinguível que transpôs o tempo e a sua intrínseca relação com a figura da Igreja Católica, grande mantenedora dessa tradição, Fábio Trubilhano e Antônio Henriques (2010) descrevem esta relação da seguinte maneira:

\footnotetext{
No contexto da história do Ocidente Medieval, reparamos a estreita comunhão entre linguagem eclesiástica e a linguagem jurídica. Como deveria ser o mundo social medievo, com inclusão da Igreja, estava impregnado do direito, como diz com propriedade o brocardo, ubi societas, ibi jus. Impossível é negar a influência profunda e indelével da Igreja no polo espiritual e político e, consequentemente, no polo jurídico da Idade Média. Tal influência deve ser medida também pela linguagem eclesiástica, o latim.

A presença do latim na linguagem jurídica remonta às épocas clássica e medieval, atravessa os séculos e inda hoje é de usus fori (TRUBILHANO; HENRIQUES, 2010).
}

Para se compreender o fazer notarial nas terras brasileiras, a partir do século XVI em diante, é preciso voltar um pouco mais no tempo, pois as práticas jurídicas aqui estabelecidas e exercidas pela coroa portuguesa ainda traziam todas as características do Direito praticada no medievo português - apesar de, historicamente, já estarmos falando da Idade Moderna, que, cronologicamente, tem seu princípio no século XV e seu fim com a Revolução Francesa (XVIII):

Quando o Estado português começa a instalar-se no Brasil, já o faz sob a forma que será conhecida como Antigo Regime. Carrega ainda instituições formadas na Idade Média, de caráter feudal ou corporativo [...]. Tal arranjo institucional passa por diversas mudanças ao longo dos três séculos de vida colonial brasileira. (LOPES, 2011, p. 212).

\section{O LATIM E O LIVRO VELHO DO TOMBO}

Ao longo do trabalho com o LVT foi possível notar a ocorrência de diversos termos e de expressões latinas. Estes termos, expressões e, por algumas vezes, trechos de argumentação despertaram alguma curiosidade quanto a sua função dentro do desenvolvimento discursivo dos documentos. Documentos estes, como já pontuado, de conteúdo jurídico.

Célia Marques Telles e Risonete Batista de Souza (2015) em artigo com o título: De verbo ad verbum: o uso do latim no Livro Velho do Tombo, analisaram o uso do latim no documento Sentença dalegacia que alcançou esteConu(en)to contraoP(adr)e Andrelobato damata sobrehumas terras naV ila velha (fólios 70r -78r) e, a partir do levantamento dos elementos latinos lá registrados, classificaram estes elementos em quatro categorias: termos, locuções, colocações e argumentos.

Os termos ora referidos são as formas lexicais grafadas ao longo do documento. Elas aparecem isoladas dentro de orações de maneira, aparentemente, aleatória. Aparentemente, pois da mesma maneira que estas palavras estão grafadas em latim, elas poderiam estar 
simplesmente grafadas em português, podendo ser apenas, uma variante gráfica ou um lapsus calami.

Já as locuções, estas são mais rígidas quanto a sua forma e, por consequência, menos adaptáveis. Entendem-se por locuções as expressões latinas, neste caso, as expressões latinas de caráter jurídico ou os brocardos. Por serem mais fixos e terem um valor semântico canonizado dentro da retórica jurídica estes elementos tem o seu momento e espaço certo para aparecer.

As colocações seguem na linha das locuções, só que essas são menos rígidas e nada canonizadas. São também expressões que aparecem no texto, mas, exatamente, pelo fato de serem menos fixas, elas não têm, necessariamente, um lugar pré-estabelecido dentro do documento para aparecerem. Ettinger assim define colocação:

Se entiende aqui por 'colocación' la tendencia sintáctico-semántico de las palabras aisladas de uma lengua a adoptar tan sólo un número limitado de combinaciones con otras palabras entre uma gran cantidad de posibles combinaciones. Pero, por motivos prácticos, no puede evitarse que también confluyan aqui criterios extralingüísticos y que deban tenerse en cuenta criterios prácticos junto a criterios semánticos y sintácticos ${ }^{2}$ (ETTINGER, 1982, p. 251, apud TELLES; SOUZA, 2015, p. 5.).

A última classificação feita por elas é o da argumentação. Aqui o latim é usado para apresentar argumentos dentro do processo judicial que se redige. É bem mais do que meiadúzia de palavras em latim que cria um brocardo ou uma colocação. São linhas e linhas a fim de convencer, com o discurso, um interlocutor também conhecedor da língua, claro, pela sua rebuscada arguição, ou para impressionar quem não conhece o seu uso.

Considerando a importância com que a língua latina, por meio dos termos e dos brocardos, despontou dentro do Direito, do fazer jurídico, no Ocidente e, mais especificamente, no caso em questão, no Brasil dos séculos XVI e XVII, pergunta-se aqui se tais termos, expressões, provérbios e textos argumentativos registrados no Livro Velho do Tombo se adequam à categorização proposta por Telles e Souza.

\section{METODOLOGIA}

Toda a análise foi feita a partir da edição semidiplomática do livro. Neste tipo de edição o nível de intervenção no texto é menor, mais profundo na conservação, por parte do editor, se comparada à edição diplomática, e ainda guarda os elementos linguísticos característicos do texto. No caso da edição semidiplomática aqui utilizada desenvolveram-se apenas as abreviaturas.

Com a edição semidiplomática (CALCABRINE; TELLES, 2007), pretendeu-se, possibilitar o acesso e a preservação do conteúdo dos volumes, a partir de critérios que restituirão e fixarão sua forma genuína, garantindo a fidedignidade e a acessibilidade necessárias para as produções acadêmico-científicas e para a consolidação de um saber público.

O corpus em questão são os 46 documentos editados do $L V T$, que abrangem cerca dos 100 fólios iniciais do mesmo. Este levantamento fora previamente feito por um bolsista do grupo. Os ditos documentos podem ser visto na relação a seguir, elaborado por Flávia Calcabrine e Célia Marques Telles, o qual dispõe das seguintes informações: a ordem que o

\footnotetext{
2 Tradução: "Entende-se aqui 'colocação' como a tendência sintático-semântica das palavras isoladas de uma língua em adotar tão somente um número limitado de combinações com outras palavras entre uma grande quantidade de possíveis combinações. Entretanto, por motivos práticos, não se pode evitar que também confluam aqui critérios extralinguísticos e que se devam ter em conta critérios práticos junto a critérios semânticos e sintáticos".
} 
documento aparece no livro, o ano do original, o título do documento, seguido do intervalo entre fólios que está compreendido dentro do livro e as páginas que ocupam na edição feita pelos monges, na Tipografia Beneditina, em 1945:

RELAÇÃO DOS DOCUMENTOS DO LVT

\begin{tabular}{|c|c|c|c|c|}
\hline $\mathbf{n}^{\mathbf{o}}$ & ano & Título & $\begin{array}{l}\text { manuscrit } \\
\text { o }\end{array}$ & 1945 \\
\hline 1. & 1619 & Sesmaria d $\{\mathrm{e}\}$ seiz legoaz da serra do Jurará & $1 r^{\circ} \cdot-3 r^{\circ}$ & p. 3-8 \\
\hline 2. & 1612 & $\begin{array}{l}\text { Sesmaria de duzentas braças de Praya ou Salgado que nos deu o Governador } \\
\text { Dom Diogo de Menezes na era de } 1612 \text { comessando do porto de Balthezar } \\
\text { Ferraz para baixo }\end{array}$ & $3 \mathrm{r}^{\mathrm{o}} \cdot-4 \mathrm{v}^{\mathrm{o}}$ & p. $9-12$ \\
\hline 3. & 1650 & $\begin{array}{l}\text { Carta de partilhas que nos deixou Belchior Dias das cazas de palha qui nos } \\
\text { vendeo na rua de Nosa Senhora da Ajuda, cujo treslado nos deixou para nosa } \\
\text { guarda, e titulo em que P. }{ }^{\circ} \text { Joam da Costa dis e em huma parte das tres dis huma } \\
\text { cota do titulo de fora q tinha este papel e treslado da escritura de venda destas } \\
\text { Cazas está neste L. }{ }^{\circ} \text { f- } 9 \text { - }\end{array}$ & $4 v^{o} .-8 v^{o}$ & p. $13-21$ \\
\hline 4. & 1650 & 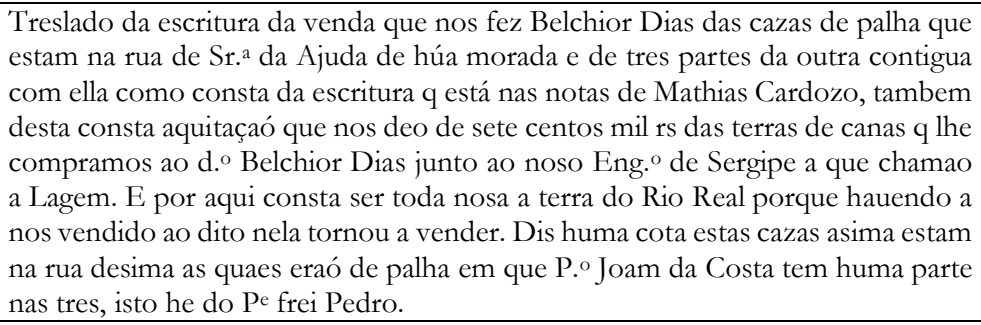 & $8 \mathrm{v}^{\mathrm{o}} \cdot-10 \mathrm{r}^{\mathrm{o}}$ & p. $22-25$ \\
\hline 5. & 1586 & $\begin{array}{l}\text { Trezlado authentico da doaçam dos Recifes e salgado defronte de } \text { Sr. }^{\mathrm{a}} \text { da } \\
\text { Conceiçam nesta Cid. }{ }^{\mathrm{e}} \text { a qual doaçaó nos trespasou Manuel Nunesde seitas, e ao } \\
\text { despois }[\dagger] \text { ela retificou seu Genro e filha como da escritura adiante a f. } 11 \text { v. } \\
\text { consta esta doaçaó foi dada por Xp }{ }^{\text {am }} \text { Add. }{ }^{\circ} \text { Genro do } \mathrm{M}^{\mathrm{el}} \text { Nunese naó por elle }\end{array}$ & $10 \mathrm{r}^{\mathrm{o}} .-11 \mathrm{v}^{\mathrm{o}}$ & p. $26-28$ \\
\hline 6. & 1614 & $\begin{array}{l}\text { Trezlado authentico da doaçam dos Recifes e salgado defronte de N. Sr. }{ }^{a} \text { da } \\
\text { Conceiçaó desta Cidade feita a este Conv. }{ }^{\text {to }} \text { por Xpam Affonço o qual a herdou } \\
\text { de seu sogro Manuel Nunes Seitas a quem hauia feito merce o G. }{ }^{\text {or }} \text { Manuel Telles } \\
\text { Barreto o que consta da escritura atras neste Lo f. } 10 \text { no fim }\end{array}$ & $11 \mathrm{v}^{\mathrm{o}} .-12 \mathrm{v}^{\mathrm{o}}$ & p. $29-31$ \\
\hline 7. & 1637 & $\begin{array}{l}\text { Folha de partilha do P.e fr Pedro de Christo porque ficou a este Conv. }{ }^{\text {to }} \\
\text { pertencendo lhe a metade de humas Cazas sitas na praia desta Cidade pegadas ao } \\
\text { canto junto ao Corpo Santo contigua com as que couberam a seu Ir fr. Hyacintho }\end{array}$ & $12 \mathrm{v}^{\mathrm{o}} \cdot-14 \mathrm{r}^{\mathrm{o}}$ & p. $32-34$ \\
\hline 8. & 1648 & $\begin{array}{l}\text { Folha de partilha dos bens que couberam a Hyacintho de Moraes e hora frei } \\
\text { Hyacintho Religiozo de Saõ Bento - pella qual tocaó a este Conu. }{ }^{\text {to }} \text { huma } \\
\text { ametade de huãs de sobrados junto ao corpo Santo digo no Canto junto ao } \\
\text { Corpo S.to }\end{array}$ & $14 \mathrm{r}^{\mathrm{o}} \cdot-15 \mathrm{v}^{\mathrm{o}}$ & p. $35-38$ \\
\hline 9. & 1612 & $\begin{array}{l}\text { Auçam que pos a este Conv. }{ }^{\text {to }} \text { Bar }^{\text {ar }} \text { ferráz contra a pose que tomamos na praya } \\
\text { desta Cidade que saó } 200 \text { braças que nos hauia dado o G. }{ }^{\text {or }} \text { Diogo de Menezes } \\
\text { nam está finda }\end{array}$ & $16 \mathrm{v}^{\mathrm{o}} .-19 \mathrm{v}^{\mathrm{o}}$ & p. $39-45$ \\
\hline 10. & 1636 & $\begin{array}{l}\text { Escritura de transaçam entre o L. }{ }^{\text {do }} \text { Ant. }{ }^{\circ} \text { Cordr. }{ }^{\circ} \text { e os R. }{ }^{\text {dos }} \text { P.es de Sam Bento de } \\
\text { humas terras abaixo de N. Sr. }{ }^{\text {a da Vila Velha }}\end{array}$ & $20 \mathrm{r}^{\mathrm{o}} \cdot-21 \mathrm{r}^{\mathrm{o}}$ & p. $46-48$ \\
\hline 11. & 1637 & $\begin{array}{l}\text { Outorga de outra escritura que fez o sobred. }{ }^{\circ} \text { L. }{ }^{\text {do }} \text { Antonio Cordeyro com os } \\
\text { frades de Sam Bento, a qual outorga he de sua } \mathrm{m} \cdot{ }^{\text {er }} \text { em q consente no sobrefacto } \\
\text { contracto da escrutura asima }\end{array}$ & $21 \mathrm{r}^{\mathrm{o}} .-22 \mathrm{r}^{\mathrm{o}}$ & p. $49-50$ \\
\hline 12. & 1639 & $\begin{array}{l}\text { Petiçam dos testamenteyros de Antonio Borges e Sentença dos sobejos das terras } \\
\text { juntas a Nosa Senhora da Graça tudo de compoziçam com obrigaçam de } 350 \\
\text { missas que diseram oz Religiozos }\end{array}$ & $22 \mathrm{r}^{\mathrm{o}} .-22 \mathrm{v}^{\mathrm{o}}$ & p. $51-52$ \\
\hline 13. & 1639 & $\begin{array}{l}\text { Papel de remataçam que se faz a Aleixo Cabral da faz. }{ }^{\text {da }} \text { de Ant. }{ }^{\circ} \text { Borgez a qual } \\
\text { como pasase a este Conv. }{ }^{\text {to }} \text { a elle se entregou este papel o qual he o seguinte }\end{array}$ & $22 \mathrm{v}^{\mathrm{o}} .-24 \mathrm{v}^{\mathrm{o}}$ & p. $52-55$ \\
\hline 14. & 1639 & $\begin{array}{l}\text { Escritura de transaçam que se fez entre os Reuerendos P.es de Sam Bento, e os } \\
\text { testamentr. }{ }^{\text {os }} \text { de Antonio Borgez, em que largam aos P. }{ }^{\text {es }} \text { os sobejoz da terra que } \\
\text { posam pertencer ao d. }{ }^{\circ} \text { Borgez na Vila Velha abaixo de N. Sr. }{ }^{a} \text { da Graça por } 350 \\
\text { misas q disseraó os Religiozos como atraz diz }\end{array}$ & $24 \mathrm{v}^{\mathrm{o}} .-25 \mathrm{v}^{\mathrm{o}}$ & p. $56-58$ \\
\hline 15. & 1639 & $\begin{array}{l}\text { Sentença dos P.es de S. Bento contra os Testam. }{ }^{\text {tros }} \text { de Antonio Borgez em que } \\
\text { se julgou pertencer a este Conv. }{ }^{\text {to }} \text { as terras de N. Sr. }{ }^{a} \text { da Graça q se mediraó, e } \\
\text { hum resto que ficaua pertencente ao d. }{ }^{\circ} \text { Borges seus testam. }{ }^{\text {tros }} \text { nos largaraó por } \\
350 \text { misas como se vé da escritura atras, de q de tudo junto tomamos pose como } \\
\text { se véneste L. }{ }^{\circ} \text { a fl } 32 \text { v. }^{\circ}\end{array}$ & $25 \mathrm{v}^{\mathrm{o}} \cdot-35 \mathrm{v}^{\mathrm{o}}$ & p. $58-71$ \\
\hline 16. & 1634 & $\begin{array}{l}\text { Sentença do conseruador dos Relig. }{ }^{\text {os }} \text { dada contra o Ld. }{ }^{\circ} \text { ou Medico Cordeiro, } \\
\text { acerca de humas terras abaixo de N. Sr. }{ }^{a} \text { de Vila Velha em que ouue conserto } \\
\text { como se vé fls } 20\end{array}$ & $33 \mathrm{v}^{\mathrm{o}} \cdot-35 \mathrm{r}^{\mathrm{o}}$ & p. $72-75$ \\
\hline
\end{tabular}




\begin{tabular}{|c|c|c|c|c|}
\hline 17. & 1636 & $\begin{array}{l}\text { Treslado da carta de sesmaria de Diogo Alz Avó de Lc. }{ }^{\circ} \text { de Brito Correa por } \\
\text { onde possuhia as terras circumvizinhas a hermida da Sr. }{ }^{a} \text { da Graça as quaes ao } \\
\text { despois herda }\{\mathrm{n}\} \text { do as o d. } .^{\circ} \text { Lc. }^{\circ} \text { de Brito Correa as deixou a este Convento com } \\
\text { a dita hermida }\end{array}$ & $35 \mathrm{v}^{\mathrm{o}} .-37 \mathrm{r}^{\mathrm{o}}$ & p. $76-79$ \\
\hline 18. & 1633 & Doação feita por Lourenço de Brito Correa das terras de N. S. da Graça & $37 \mathrm{v}^{\mathrm{o}} .-38 \mathrm{r}^{\circ}$. & p. $79-80$ \\
\hline 19. & 1568 & 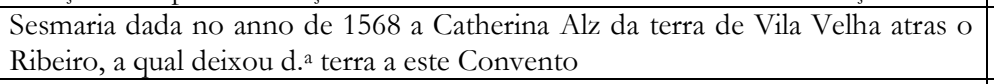 & $38 \mathrm{r}^{\circ} .-40 \mathrm{r}^{\circ}$ & p. $81-84$ \\
\hline 20. & 1654 & $\begin{array}{l}\text { Trezlado da doaçam da Igreja de Nossa Senhora da Graça feita a este conuento } \\
\text { Por Cn.a Alz e das terras circumvizinhas e prata de seu uzo e o mais que della } \\
\text { constará aqual doaçam foi feita na hora de } 1586\end{array}$ & $40 \mathrm{r}^{\circ} .-44 \mathrm{v}^{\circ}$ & p. $85-93$ \\
\hline 21. & 1593 & $\begin{array}{l}\text { Escritura de venda feita p este Conuento a Simam frz o cego de humas cazas } \\
\text { sitas no Ribeiro, e brejo desta Cidade }\end{array}$ & $45 \mathrm{r}^{\circ} \cdot-47 \mathrm{r}^{\circ}$ & p. $94-96$ \\
\hline 22. & 1658 & $\begin{array}{l}\text { Escritura de venda que fez Ignes Machada Veuua aos Reuerendos Padres de Sam } \\
\text { Bento desta Cidade de humas terras sitas junto da Sr. }{ }^{a} \text { da Vitoria da p. } .^{\text {te }} \text { esquerda } \\
\text { da estrada publica indo p. } .^{a} \text { a d. } .^{a} \text { Igreja da Sr. } .^{a}\end{array}$ & $47 \mathrm{r}^{\mathrm{o}} \cdot-48 \mathrm{r}^{\circ}$ & p. $97-99$ \\
\hline 23. & 1580 & $\begin{array}{l}\text { Escritura doz Chaos e casas que foram do Pe Vigario Matrheus Vas digo do Pe } \\
\text { Niculao Glz que comprou a Ayres da Rocha Peixoto e a sua mulher sitas na Vila } \\
\text { velha }\end{array}$ & $48 \mathrm{r}^{\circ} .-49 \mathrm{v}^{\mathrm{o}}$ & $\begin{array}{l}\text { p. } 99- \\
102\end{array}$ \\
\hline 24. & 1630 & $\begin{array}{l}\text { Testamnento de Manoel Nunes Paiua em q deixa a este Convento por herdr. } \\
\text { em } \text { p. }^{\text {te }} \text { de seus bens, com os encargos nelle insertos, e asim mais huma escritura } \\
\text { de venda de huás terras do d. }{ }^{\circ} \text { a Dom. }{ }^{\circ} \text { Lopez e a sentença de Manoel Reis } \\
\text { Sanches \&c }\end{array}$ & $49 \mathrm{v}^{\mathrm{o}} .-56 \mathrm{r}^{\mathrm{o}}$ & $\begin{array}{l}\text { p. } 103- \\
114\end{array}$ \\
\hline 25. & 1634 & $\begin{array}{l}\text { Escritura do conserto q ouue entre Luis Vaz De Paiua, e outras Pesoas com este } \\
\text { Conuento como herdeito de Manuel Nunez Payua }\end{array}$ & $56 \mathrm{r}^{\circ} .-60 \mathrm{r}^{\circ}$ & $\begin{array}{l}\text { p. } 114- \\
122 \\
\end{array}$ \\
\hline \multirow[t]{2}{*}{26.} & 1609 & $\begin{array}{l}\text { Sesmaria de Luis Vas de Paiua e seu irmaó Mel Nunes de Paiua de seis legoas de } \\
\text { terras nos lemites do Jacuipe the o Rio de Pojuca, nos lados de Jorge de Mello } \\
\text { Coutinho e Manoel Lopez de Saá q estão lancadas neste Liuro a fl } 160 \text { por diante }\end{array}$ & $60 \mathrm{r}^{\circ} .-61 \mathrm{r}^{\circ}$ & $\begin{array}{l}\text { p. } 122- \\
124\end{array}$ \\
\hline & & Mapa da Terra Noua & $61 v^{\circ}$. & $\begin{array}{l}\text { Não } \\
\text { reprodu } \\
\text { zido }\end{array}$ \\
\hline 27. & 1632 & $\begin{array}{l}\text { Escritura de venda de humas cazas junta as portas de S. Luzia ou S. Bento feita } \\
\text { por Fran.co de Lapenha a Matheus vaz Marsineyro }\end{array}$ & $61 \mathrm{v}^{\mathrm{o}} .-63 \mathrm{r}^{\circ}$ & $\begin{array}{c}\text { f. } 125- \\
127\end{array}$ \\
\hline 28. & 1628 & $\begin{array}{l}\text { Escritura de aforamento que fez o Prou }{ }^{\text {or }} \text { e Irmaos da Caza da Santa Miz. }{ }^{a} \text { a } \\
\text { Matheus vaz da terra em q estáo as cazas q Constaó da escritura atras proxima } \\
\text { compradas a Frc. }{ }^{\circ} \text { de LaPenha }\end{array}$ & $63 \mathrm{r}^{\circ} .-64 \mathrm{v}^{\mathrm{o}}$ & $\begin{array}{l}\text { f. } 128- \\
130\end{array}$ \\
\hline 29. & 1616 & $\begin{array}{l}\text { Escritura de hums chaons junto a Sam Bento que a Fernaó Pires Manso vendeo } \\
\text { Nicolao Antunes }\end{array}$ & $64 v^{0} \cdot-68 r^{\circ}$ & $\begin{array}{c}\text { p. } 131- \\
137 \\
\end{array}$ \\
\hline 30. & 1577 & $\begin{array}{l}\text { Escritura pela qual foram dadas em dote húns chaos e cazas sitos na Vila Vela a } \\
\text { Ayres de Rocha as que ao despois oune p compra do Pe Vigr. }{ }^{\circ} \text { MatheusVas detras } \\
\text { de N. S. da Vitoria digo do P. } \text { Vigr. }^{\circ} \text { Niculao Glx }\end{array}$ & $68 \mathrm{r}^{\circ} .-69 \mathrm{r}^{\circ}$ & $\begin{array}{l}\text { p. } 137- \\
139\end{array}$ \\
\hline 31. & 1658 & $\begin{array}{l}\text { Escritura de venda que fes Ignez Machada aos Reverendos Padres de Saó Bento } \\
\text { de huás teros q foraó do Vigario Matheus vas e de huá reuua na Victoria }\end{array}$ & $69 \mathrm{v}^{\mathrm{o}} .-70 \mathrm{r}^{\circ}$ & $\begin{array}{c}\text { p. } 140- \\
142\end{array}$ \\
\hline 32. & 1634 & $\begin{array}{l}\text { Sentença da legacia que alcançou este Conu. }{ }^{\text {to }} \text { contra o P. }{ }^{\text {e Andre Lobato da mata }} \\
\text { sobre humas terras na Vila velha }\end{array}$ & $70 \mathrm{r}^{\mathrm{o}} \cdot-78 \mathrm{r}^{\mathrm{o}}$ & $\begin{array}{c}\text { p. } 142- \\
157\end{array}$ \\
\hline 33. & 1645 & $\begin{array}{l}\text { Testamento de Maris Roiz de oLiur.a em que nos deixou tres moradas de cazas } \\
\text { sobradadas ao guindaste e outras deixas com emcargo de certas misas como dele } \\
\text { consta e foi Casada com Anto Frz. }\end{array}$ & $78 \mathrm{r}^{\circ} .-79 \mathrm{v}^{\mathrm{o}}$ & $\begin{array}{l}\text { p. } 158- \\
161\end{array}$ \\
\hline 34. & 1649 & $\begin{array}{l}\text { Escritura de auto de pose que tomou este mosteiro das cazas deixadas no } \\
\text { testamto asima de } \mathrm{M}^{\mathrm{a}} \text { Roiz de oLiur. }{ }^{\mathrm{a}} \text { sitas no guindaste }\end{array}$ & $79 \mathrm{v}^{\mathrm{o}} .-80 \mathrm{r}^{\mathrm{o}}$ & $\begin{array}{l}\text { p. } 161- \\
162 \\
\end{array}$ \\
\hline 35. & 1652 & $\begin{array}{l}\text { Escritura de uenda que a este Conuento fez Adrianna Gomes por seu Procurador } \\
\text { Antonio da Mota das benfeitorias de húas cazas sitas ao guindaste }\end{array}$ & $80 \mathrm{r}^{\circ} .-82 \mathrm{r}^{\circ}$ & $\begin{array}{c}\text { p. } 162- \\
166\end{array}$ \\
\hline 36. & 1652 & $\begin{array}{l}\text { Sentença de Lic. }{ }^{a} \text { para Adrianna Gomes poder vender asd cazas asima junto ao } \\
\text { guindaste em que hia o quinháo doz orfaos seuz filhos }\end{array}$ & $82 \mathrm{r}^{\circ} .-83 \mathrm{r}^{\circ}$ & $\begin{array}{l}\text { p. } 166- \\
169\end{array}$ \\
\hline 37. & 1698 & $\begin{array}{l}\text { Escritura de uenda que fez o Tenente Gnl.da Artelharia Sebastiam de Araujo e } \\
\text { Lima a este Conv. to de duas braças de terra }\{\mathrm{e}\} \mathrm{m} \text { que está o guindaste }\end{array}$ & $83 r^{\circ} .-85 r^{\circ}$ & $\begin{array}{l}\text { p. } 169- \\
172\end{array}$ \\
\hline 38. & 1601 & $\begin{array}{l}\text { Escritura de uenda que a este Conu.to fes o Coronel Gon. }{ }^{\text {lo }} \text { Rausaco de húa sorte } \\
\text { de terra sita abaixo do guindaste dos ditos Religiozos }\end{array}$ & $85 \mathrm{r}^{\circ} .-86 \mathrm{r}^{\circ}$ & $\begin{array}{c}\text { p. } 173- \\
175\end{array}$ \\
\hline 39. & 1630 & $\begin{array}{l}\text { Escritura de aforamto doz chaos em que Antonio frz fez as Cazas junto ao } \\
\text { guindaste que noz ficarão por morte de sua mulher Maria Roiz }\end{array}$ & $88 \mathrm{r}^{\mathrm{o}} .-89 \mathrm{r}^{\mathrm{o}}$ & $\begin{array}{l}\text { p. } 180- \\
182\end{array}$ \\
\hline 40. & 1698 & $\begin{array}{l}\text { Escritura de uenda que a este Conun. }{ }^{\text {to }} \text { fes o Coronel An. }{ }^{\text {to }} \text { da Silua Pimentel de } \\
\text { seiz braças de terra abaixo das portas de Sam Bento por preço de } 420 \mathrm{mrs} \text { de q } \\
\text { lhe ficaraó pagando juros }\end{array}$ & $85 \mathrm{v}^{\mathrm{o}} .-88 \mathrm{r}^{\mathrm{o}}$ & $\begin{array}{l}\text { p. } 176- \\
179\end{array}$ \\
\hline 41. & 1649 & $\begin{array}{l}\text { Escritura do distrato, que se fes das Cazas de Maria Roiz ao guindaste que seu } \\
\text { marido Antonio frz deixou aretadas por } 155 \mathrm{mrz} \text { a Frc } \text { Foiz Roza }^{\circ}\end{array}$ & $89 \mathrm{r}^{\circ} .-90 \mathrm{r}^{\circ}$ & $\begin{array}{l}\text { p. } 183- \\
185\end{array}$ \\
\hline 42. & 1667 & $\begin{array}{l}\text { Escritura, e pose de duas moradas de Cazas q temos na travessa de - Nicolao } \\
\text { Aranha - por duas Capellas de missas que nos fes doassão dellas pedro } \\
\text { Gonçalves Meyra }\end{array}$ & $90 \mathrm{r}^{\mathrm{o}} .-92 \mathrm{v}^{\mathrm{o}}$ & $\begin{array}{l}\text { p. } 186- \\
191\end{array}$ \\
\hline
\end{tabular}




\begin{tabular}{|c|c|c|c|c|}
\hline 43. & 1640 & 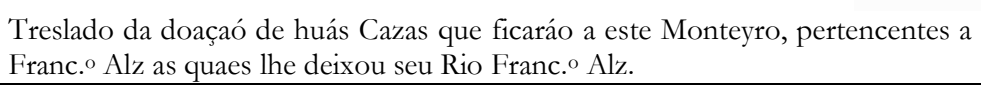 & $92 \mathrm{v}^{\mathrm{o}} .-97 \mathrm{v}^{\mathrm{o}}$ & $\begin{array}{l}\text { p. } 192- \\
203\end{array}$ \\
\hline 44. & 1697 & Bahya de todos os Sanctos e pousadas de mim & $98 \mathrm{r}^{\circ}$. & p. 204 \\
\hline 45. & 1650 & $\begin{array}{l}\text { Treslado da escritura de uenda que fez Manoel da Motta ao Mosteiro de Sam } \\
\text { Bentto das Cazas sobradadaz na rua de N. S. da Júda, e outras terreas na rua de } \\
\text { baixo q se continuão pello quintal }\end{array}$ & $98 \mathrm{r}^{\circ} .-99 \mathrm{r}^{\circ}$. & $\begin{array}{l}\text { p. } 205- \\
208\end{array}$ \\
\hline 46. & 1640 & $\begin{array}{l}\text { Sentensa de folha de partilha que deu Manoel da Motta aos reuerendos Padres } \\
\text { de Sam Bentto pertencente a escritura atraz pella qual constase sua a propriedade } \\
\text { que uendeo, pertençente a sua m. }{ }^{\text {er }} \text { Phelipa Barboza }\end{array}$ & $99 \mathrm{v}^{\mathrm{o}} .-102 \mathrm{r}^{\circ}$. & $\begin{array}{l}\text { p. } 208- \\
215\end{array}$ \\
\hline
\end{tabular}

É curioso observar nesta lista que não existe ordem alguma na disposição dos documentos: não há se seguirmos o conteúdo de cada documento, ou seja, não estão dispostos a fim de criar um "continuum processual" e também não há se observarmos a cronologia dos originais. Em seguida, após o levantamento, foi feita uma análise de todo o material localizado, considerando qual o teor que este elemento traz consigo para o efeito retórico do argumento no documento, enfim "verificar como os brocardos funcionam como forma de argumentação" (TRUBILHANO; HENRIQUES, 2010, p.100).

Seguindo o levantamento e a funcionalidade discursiva destes termos, brocardos jurídicos e trechos encontrados, foram separados seguindo a categorização proposta por Telles e Batista (2016) para os elementos lá encontrados. A recordar, a categorização dividese em: termos, locucões, colocações e os argumentos.

\section{DADOS OBSERVADOS}

Ao fim do levantamento foram encontrados 68 (sessenta e oito) elementos em língua latina, caracterizando, desta forma, 100\%.

Gráfico 1 - Ocorrência de elementos da Língua Latina

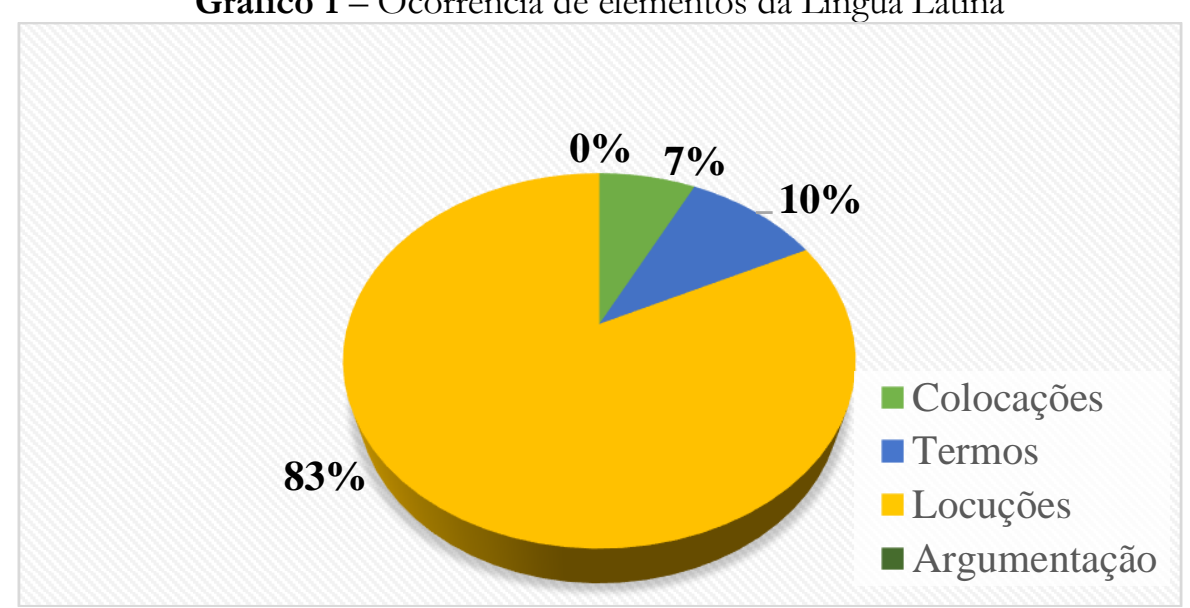

Fonte: Dados da pesquisa.

Deste total, 5 (cinco) elementos foram classificados como colocações, representando $7 \%$ do total. Neste grupo encontram-se elementos como os observados:

\begin{tabular}{|c|c|c|}
\hline in scriptis & "nos escritos" & f.72.v, L.38 \\
\hline $\begin{array}{l}\text { saepe, saepius, saepissimé, instanter, } \\
\text { instantius, instantissimé vno }\end{array}$ & $\begin{array}{l}\text { "frequentemente, mais frequentemente, frequentissimamente, sem demora, } \\
\text { sem muita demora, rapidissimamente ao mesmo tempo, para o mesmo fim e } \\
\text { contexto" }\end{array}$ & $\begin{array}{l}\text { f.72.v, } \\
16 / 17\end{array}$ \\
\hline
\end{tabular}


A segunda menor ocorrência é dos termos. Estes foram representados por 7 (sete) elementos dentro do total de 68. Apenas três termos apareceram: simplex, que ocorre 3 (três) vezes; e nibil, que ocorrem 2 (duas) vezes cada, como se pode ver:

\begin{tabular}{c|c|c} 
nibil & nada, de modo algum & f.46v, L.2, 126 \\
\hline simplex & simples, único & f.72.v, L.20/21, L.24, L.32
\end{tabular}

A expressão insolidum fora considerado um termo, apesar da scriptio continua, deve ser lida in solidum (inteiramente, solidariamente). Dois fatores foram considerados para tal: a recorrência da escrita do elemento em um significativo intervalo por diferentes scriptores, scriptor 4 (f.30r) e scriptor 6 (f.51r); e a falta de uma regularidade na grafia das palavras no período em que o texto está compreendido, podendo caracterizar um lapsus calami.

As locuções detêm a grande maioria dos elementos ora classificados, possuindo um total de 56 (cinquenta e seis) ocorrências. O grande responsável por este número é o et coetera (e o resto, e as demais coisas), ele se repete 28 (vinte e oito) vezes ao longo dos documentos. O segundo elemento mais presente é ex causa (em atenção à causa) sendo reproduzido 8 (oito) vezes. Outros elementos também recorrentes foram:

\begin{tabular}{c|c|c} 
insolidum & inteiramente, solidariamente & f.30r, L.30; f.51r, L.36 \\
\hline de verbo ad verbum & palavra por palavra & f.21v, L.11; f.1r, L.27/28; f.10v, L.17; \\
f.72v, L.11
\end{tabular}

Para encerrar, temos os argumentos que não apresentaram dados algum. Dentro destes 46 documentos em nenhum momento os escrivães se valeram do latim para argumentar, nem em causa próprio, como de costume, tampouco contra, o que seria bastante contrassensual.

\section{CONCLUSÃO}

Este trabalho é o início de mais uma pequena empreitada que tem como protagonista os Livros de Tombo do Mosteiro de São Bento da Bahia. Neste pequeno recorte o intento foi o de observar o comportamento das expressões, termos, elementos latinos neste que é o mais antigo livro da coleção de Livros do Tombo, o Livro Velho, tentando encaixá-los à classificação proposta por Telles e Souza.

Até este momento, houve êxito. O estudo destes elementos se dá, pois acredita-se que estes preservem no fazer notarial do Brasil Colônia, os traços característicos da retórica e da argumentação no Direito nascido em Roma, assim como a língua praticada pela Madre Igreja, sendo assim mantenedora desta tradição. Observa-se também o comportamento notarial estabelecido no Brasil pela Coroa Portuguesa, que trouxe consigo muito do processo notarial do medievo português, caracterizando assim a atuação dos Tabelionatos de Notas no Brasil. O trabalho irá se estender para todo o Livro Velho e o Livro III do Tombo. 


\section{REFERÊNCIAS}

CALCABRINE, Flavia Daianna; TELLES, Célia Marques. 2007. O Livro Velho do Tombo do Mosteiro de São Bento da Babia. In: SEMINÁRIO DE PESQUISA E PÓS-GRADUAÇÃO, 22. Salvador: PROPPG. 2007.

ETTINGER, Stefan. Formacion de palabras y fraseología en la lexicografía. In: HAENSCH, G.; WOLF, L.; ETTINGER, S.; WERNER, R. La lexicografía: de la lingüística teórica a la lexicografía práctica. Madrid: Gredos. 1982. p. 233-258. Citado apud TELLES, Célia Marques; SOUZA, Risonete Batista. 2016. De verbo ad verbum: o uso do latim no Livro Velho do Tombo. Estudos Linguísticos e Literários, Salvador.

LOPES, José Reinaldo de Lima. O direito na história: lições introdutórias. 3 ed. São Paulo: Atlas. 2011.

LIVRO VELHO DO TOMBO DO MOSTEIRO DE SÃO BENTO DA BAHIA DA CIDADE DO SALVADOR. Bahia: Tipografia Beneditina. 1945.

LOSE, Alícia Duhá et al. Livro Velho do Tombo do Mosteiro de São Bento da Babia (Salvador, 15821750): edição semidiplomática e análise da formação do pensamento das famílias católicas baianas. Salvador: Faculdades São Bento. Projeto de pesquisa. 2006.

MARTÍNEZ ORTEGA, Maria de los Ángeles. La lengua de los siglos XVIy XVII através de los textos jurídicos: los pleitos civiles de la escribanía de Alonso Rodríguez. Valladolid: Secretariado de Publicaciones e Intercambio Editorial; Univ. de Valladolid. 1999.

TELLES, Célia Marques. Fontes primárias para a sócio-bistória da Babia: o Livro Velho do Tombo do Mosteiro de São Bento da Bahia. Scripta Pbilologica. Feira de Santana, BA, v. 4, 2008. p.102118.

TELLES, Célia Marques; SOUZA, Risonete Batista. De verbo ad verbum: o uso do latim no Livro Velho do Tombo. Estudos Linguísticos e Literários. Salvador. 2015.

TRUBILHANO, Fabio; HENRIQUES, Antônio. Linguagem jurídica e argumentação: teoria e prática. São Paulo: Atlas. 2010. 